\title{
Strategies for the Implementation of an Electronic Fracture Risk Assessment Tool in Long Term Care: A Qualitative Study
}

\section{Yuxin Bai}

McMaster University

Caitlin McArthur ( $\nabla$ caitlin.mcarthur@dal.ca )

Dalhousie University

George loannidis

McMaster University

Lora Giangregorio

University of Waterloo

\section{Sharon Straus}

University of Toronto

Alexandra Papaioannou

McMaster University

\section{Research Article}

Keywords: long-term care, evidence-based, guidelines, knowledge translation, fracture risk, clinical assessment protocol

Posted Date: May 6th, 2021

DOI: https://doi.org/10.21203/rs.3.rs-253254/v2

License: (9) This work is licensed under a Creative Commons Attribution 4.0 International License.

Read Full License

Version of Record: A version of this preprint was published at BMC Geriatrics on August 21 st, 2021. See the published version at https://doi.org/10.1186/s12877-021-02388-3. 


\section{Abstract}

Background: Older adults in long-term care (LTC) homes experience high rates of fractures, which are detrimental to their quality of life. The purpose of this study is to identify and make recommendations on knowledge translation interventions to implementing an evidence-based Fracture Risk Clinical Assessment Protocol (CAP) in LTC.

Methods: Following the Behaviour Change Wheel framework, we conducted focus group interviews with 32 LTC stakeholders (e.g. LTC physicians) to identify barriers and facilitators, suggest intervention options, and discuss whether the identified interventions were feasible. The interviews were transcribed verbatim and analyzed using thematic content analysis.

Results: The intervention themes that met the APEASE criteria were minimizing any increase in workload, training on CAP usage, education for residents and families, and persuasion through stories. Other intervention themes identified were culture change, resident-centred care, physical restructuring, software features, modeling in training, education for staff, social rewards, material rewards, public benchmarking, and regulations.

Conclusions: To implement the Fracture Risk CAP in LTC, KT interventions centred around minimizing any increase in workload, training on CAP usage, providing education for residents and families, and persuading through stories may be used. Results from this work will improve identification and management of LTC residents at high fracture risk and could inform the implementation of guidelines for other conditions in LTC homes.

\section{Introduction}

Older adults experience significant deterioration in their health-related quality of life after a fracture of the hip or spine, as well as changes in their capacity for mobility, self-care, and daily activities [1, 2]. Up to $85 \%$ of long-term care (LTC) residents have osteoporosis, a skeletal disease characterized by bone deterioration and increased fracture risk [3]. Compared to age and sex-matched older adults in the community, LTC residents experience a higher fracture rate, lower likelihood of regaining their previous level of function, and higher chance of dying within 3 months post-fracture [4-7]. Despite the high incidence and severe consequences of fractures, guidelines for fracture risk assessment and management are underutilized in LTC $[8,9]$. Furthermore, LTC-specific challenges make it difficult to use general fracture risk assessment tools. Indeed, while the median survival rate among residents were reported to be from 28-41 months [10], the Canadian Association of Radiologists and Osteoporosis Canada (CAROC) tool [11] and the Canadian WHO Fracture Risk Assessment Tool (FRAX) [12] estimate a 10-year fracture risk. Additionally, cognitive impairment and frailty among LTC residents are not considered in CAROC or FRAX though those factors may contribute to fractures [13].

To address the barriers to fracture assessment and management [14), our team developed an evidencebased Fracture Risk Clinical Assessment Protocol (CAP) [15]. CAPs are decision-making tools that 
identify residents at risk for adverse outcomes and provide risk level-specific recommendations to clinicians [16]. CAPs are triggered by embedded risk algorithms in mandated LTC resident assessments (RAI 2.0 and interRAl instrument) across Canada [17]. The Fracture Risk CAP is triggered by the embedded Fracture Risk Scale (FRS) which identifies residents at high fracture risk and delineates fracture prevention interventions [18]. The suggested prevention interventions are based on LTC specific fracture prevention recommendations that were developed using the GRADE approach [19]. Our team has developed the Fracture Risk CAP, and the next step is to determine the best way to support implementation to change practice.

Developing evidence-based guidelines and tools (e.g., the Fracture Risk CAP) is an early step in sustainable practice change $[20,21]$. Indeed, failure to implement well-validated interventions is a widespread problem [22]. Therefore, there is an urgent need for finding the best ways to implement guidelines and tools in LTC [23]. Due to the ineffectiveness of trial-and-error approaches to guideline uptake, implementation scientists call for theory-informed approaches to knowledge translation (KT) [24]. The Behaviour Change Wheel (BCW) is an evidence-based framework to guide implementation of interventions [25]. The guide is divided into three main stages: 1) Understand the behaviour, 2) Identify intervention options, and 3) Identify content and implementation options [25]. The BCW invites researchers to first identify the sources of behaviour (e.g. barriers and facilitators) in terms of COM-B components (Capability, Opportunity, Motivation are needed to change Behaviour) [25]. Next, it connects the COM-B components to nine intervention functions (education, training, environmental restructuring, restriction, coercion, incentivization, persuasion, modelling, enablement) that could change each of the COM-B components to overcome barriers and leverage facilitators [25]. Finally, the BCW encourages researchers to consider modes of delivery and select specific interventions using the APEASE criteria, which asks whether the intervention is Affordable, Practicable, Effective, Acceptable, Safe, and promotes Equity [25]. The BCW constructs and APEASE are defined in Additional File 1.

Guided by the BCW, the aims of the current study are to 1) identify KT interventions based on barriers and facilitators to guideline implementation in LTC; and 2) to make recommendations for KT interventions to implement the Fracture Risk CAP.

\section{Methods}

Our study was guided by the three stages of the BCW (Fig. 1).

\section{Setting and participants}

We aimed to recruit a multidisciplinary group of stakeholders with expertise in fracture prevention in LTC from across Canada. We invited by email experts in LTC and fracture prevention to participate in a national face-to-face meeting to discuss preventing fractures in LTC. The health professionals were chosen based on their experience working in LTC or their expertise in fracture prevention. LTC residents and family members who were invited had prior experiences with fractures. All participants were recruited 
through word of mouth or were known to the team. Participants included physicians (e.g. family physicians, geriatricians), pharmacists, physiotherapists, kinesiologists, nurses, researchers, dieticians, LTC residents, family members, and representatives from associations including Osteoporosis Canada, LTC associations, an electronic medical record vendor, and family councils in LTC (Table 1). The meeting took place in October 2019 in a hotel meeting room. At the meeting, participants were divided into six focus groups and assigned seating to ensure equal representation of different stakeholders in each group. Focus group discussions lasted approximately 50 minutes in total and each group had one facilitator from the research team. Focus groups were guided by a semi-structured interview guide developed to elucidate KT interventions and APEASE criteria evaluation (Additional File 2).

\section{BCW Stage 1 - Understanding the behaviour}

Prior to the meeting, the research team conducted a systematic review which identified barriers and facilitators to implementing evidence-based guidelines in LTC (results reported elsewhere). The barriers and facilitators identified from the systematic review were mapped on to COM-B components (e.g. social opportunity) of the BCW.

At the meeting, we first presented information about fractures in LTC, the Fracture Risk CAP, KT, and the $\mathrm{BCW}$ and how to use it to the participants. The results of the previously completed systematic review and COM-B mapping were also presented to the participants. Next, participants were asked to discuss any additional barriers and facilitators they identified from their experiences that were not in our systematic review.

\section{BCW Stage 2 and 3 - Identify intervention options and Identify content and implementation options}

Each focus group was assigned one of the six most frequently identified barriers from our systematic review (acceptance of guidelines, knowledge gaps, time constraints and inadequate staffing, reluctance to change, competing priorities, and compromised communication and information flow) and given a hand-out guide which included a description of the barrier, the linked COM-B component, and associated intervention categories (Additional File 3).

Participants were asked to identify specific KT interventions that correspond to broad BCW intervention functions from their experience that could be used to help implement the Fracture Risk CAP. Participants were then asked to discuss whether the interventions they identified met the APEASE criteria. Participants were not asked explicitly to discuss modes of delivery, but the topic came up naturally as they discussed intervention options and the APEASE criteria.

\section{Data collection and analysis}

All focus group discussions were audio-recorded and transcribed verbatim by YB. For BCW Stage 3, each focus group facilitator also filled out notes on the barrier-to-intervention handouts given to each table. The data were analyzed using thematic content analysis [26, 27]. First, two team members (YB and CM) 
read the transcripts thoroughly to become familiar with the content of the transcripts. Next, the same team members independently and inductively identified relevant codes and condensed them into potential themes based on patterns of meaning. Subsequently, YB and CM reviewed the initial themes generated by checking them against the dataset and deliberated on discrepancies to split, combine, or discard them until consensus was reached. Finally, YB and CM redefined and named the themes. For BCW stage 1, barriers and facilitators themes were identified and presented with illustrative quotes. For BCW stage 3, descriptions of interventions detailed by the participants were grouped into themes and presented by the intervention function with which they were associated [27]. We also present modes of delivery associated with the interventions and discussion points for the APEASE evaluation. This project was approved by the Hamilton Integrated Research Ethics Board.

\section{Results}

Of the 47 experts we invited, 32 attended and participated in focus group discussions (Table 1). 
Table 1

Participant characteristics

\begin{tabular}{|ll|}
\hline Characteristics & $\mathbf{N}=32$ \\
\hline Health Professionals & $10(31.3)$ \\
\hline Physician & $3(9.4)$ \\
\hline Pharmacist & $2(6.3)$ \\
\hline Physiotherapist & $1(3.1)$ \\
\hline Kinesiologist & $2(6.3)$ \\
\hline Rurse & $2(6.3)$ \\
\hline Diesearcher & $3(9.4)$ \\
\hline Residents and Family Members & $1(3.1)$ \\
\hline Long-term care resident & $1(3.1)$ \\
\hline Family member & \\
\hline Representatives from Affiliated Organizations & $2(6.3)$ \\
\hline Osteoporosis Canada & $2(6.3)$ \\
\hline Long-term care associations & $1(3.1)$ \\
\hline Electronic medical record vendor & $1(3.1)$ \\
\hline Ontario Association of Residents' Councils & $1(3.1)$ \\
\hline Family Councils Ontario & \\
\hline
\end{tabular}

\section{Barriers and facilitators to implementing the Fracture Risk CAP}

Focus group participants identified several barriers and facilitators in the context of fracture prevention in LTC (Table 2). Specifically, barriers included language barriers between staff and residents or family members, lack of access to the required software, lack of expertise in the use of technology, training to a limited population. In particular, poor integration of physicians in the LTC care team was mentioned by multiple focus groups. Additional facilitators identified include having multiple checkpoints or another time to carry out an intervention if it was missed, sharing best practices across the LTC sector, technology, value propositions, and existing avenues to implement changes in LTC homes.

Table 2. Barriers and facilitators specific to fracture prevention 
Language

barrier between

staff and

residents/family

Lack of access

to required

software

Lack of

expertise in the

use of

technology

Training to a

limited

population
"Perhaps language barriers? [...] knowing the complexity and the range of residents and families whereas staff may not speak the language."

"So in my home, we don't use PointClickerCare [software]. So lack of access to the actual software or information systems."

"Sometimes [technology] can also be a barrier.

It can. Yeah. If it's not implemented correctly. It also depends on the level on the level of expertise with technology that the staff has."

"We could do a lot of work to put together the CAP, and we do a lot of training to a very small proportion of people on what those CAPs mean, but the individuals that are really implementing theses at a clinical level, they never see these values"

Lack of physician involvement
"Any time physicians are involved and are a key player in an intervention, they are not...they don't have the same vested interest because they're not really involved in quality improvement in our villages, because they have their own separate private practice."

\section{Facilitator \\ Checkpoints - another time to carry out the intervention if it was missed due to time constraints \\ Sharing best practices across the care home sector}

Technology

Value proposition

Existing avenues to implement change in LTCs
Quote

"Maybe they also need more than one point of care. So, if it's missed because of the lack of time and resources. You never know what's happening in a day. There should be another checkpoint.

\begin{abstract}
"A system that allows your support homes to share best and leading practices with other homes. As an alternative to compliance inspectors, facilitators of knowledge exchange and translation across the sector."
\end{abstract}

"definitely technology. Some technology that can help facilitate
implementation."

"Every time I knew there was something they were going to be losing, I try to find, what are they gaining? So we have a conversation here, can't do this for us, but you can do this for us"

"I think a facilitator is that long-term care is really used to changing and there are a lot of the existing avenues that you can use to implement change, like best practice spotlights, all of the medication reduction that we've done related to antipsychotic use...residents and family councils, like there are huge number of avenues that you can access if you're trying to make a change and we're really used to change."

\section{Interventions, modes of delivery, and APEASE}

Within the training function of the BCW, participants suggested mandatory training during onboarding and a propagative strategy where early change adopters are trained to train other staff on the usage of 
the Fracture Risk CAP. The participants believed that the intervention met the APEASE criteria as long as it does not shift the focus away from other tasks such as skin assessments for pressure ulcer prevention. Various interventions were identified in the environmental restructuring function. In particular, participants suggested workplace culture changes that promote teamwork among interdisciplinary staff and having consistent staffing, while cautioning that there may be risk of individuals performing tasks for which they were not trained. Another theme that many focus groups discussed was resident-centred care, although participants were concerned that lack of interest and availability from family may hinder the practicability, effectiveness, and acceptability of interventions in this theme. One focus group strongly emphasized integration of the Fracture Risk CAP into existing processes, which serves to minimize any additional workload placed on the staff and which they believed met all of the APEASE criteria.

Under enablement, the focus groups suggested developing software features that would facilitate the use of the Fracture Risk CAP. However, participants also pointed to limitations where developing software features may not be practicable due to development time and a side effect of taking the focus away from other important health conditions. Modeling was discussed in terms of building it into training using case studies and role-playing. For example, training sessions that incorporate multiple disciplines at the training stage could model the desired interdisciplinary collaboration in LTC homes. Moreover, education was grouped into education for staff and education for residents and their families. Discussions regarding education for staff centered around tailoring to specific roles, patient focused education, and taking an interprofessional approach with emphasis on physician involvement. Micro-learning and elearning were also suggested to reduce costs and fatigue. On the other hand, education for residents and families was described both in terms of the importance of guidelines and how to advocate for their use, to be delivered through a pamphlet with actionable items and in-person during resident-family conferences. Participants believed that education should be targeted to residents and families of residents with high fracture risk, available in multiple formats, and easy to understand.

Within persuasion, participants advised to highlight stories that show the impact of fractures and the benefit of following the Fracture Risk CAP. Highlighting stories could be achieved using various modes of delivery and met the APEASE criteria as long as any visuals used are made for the homes, exhibit racial and gender diversity, and are available in multi-media formats. Incentivization was discussed in the form of social and material rewards for LTC homes with decreased fracture rates. Participants also critiqued the current funding model in Ontario where more funding is allocated based on the severity of the residents' conditions in the LTC home, as they believed that it decreases the incentive for functional improvement. Furthermore, public benchmarking was proposed as a way of coercion by two focus groups, although one group pointed to a potential side effect, underreporting of cases of fractures. Finally, participants suggested some regulations that may be put in place as a form of restriction, which were ensuring that there is a care plan associated with an FRS score as a criterion for prescribing osteoporosis medication and changing policy to mandate use of up-to-date Fracture Risk Assessment and Prevention Tools. 
A summary of BCW intervention functions, interventions in the context of implementing the Fracture Risk CAP in LTC, their associated modes of delivery, and the APEASE criteria discussed in the focus groups is provided in Table 3. 
Table 3

Potential interventions, mode of delivery, and APEASE criteria

\begin{tabular}{|c|c|c|c|c|}
\hline $\begin{array}{l}\text { BCW } \\
\text { Intervention } \\
\text { function }\end{array}$ & Themes & $\begin{array}{l}\text { Interventions in the } \\
\text { context of implementing } \\
\text { the Fracture Risk CAP }\end{array}$ & Mode of Delivery & $\begin{array}{l}\text { Does it meet } \\
\text { APEASE? }\end{array}$ \\
\hline \multirow[t]{3}{*}{ Training } & \multirow[t]{3}{*}{$\begin{array}{l}\text { Training on } \\
\text { CAP usage }\end{array}$} & $\begin{array}{l}\text { - Mandatory onboarding } \\
\text { training }\end{array}$ & \multirow[t]{2}{*}{$\begin{array}{l}\text { Online or in- } \\
\text { person }\end{array}$} & \multirow{2}{*}{$\begin{array}{l}\text { Yes, with } \\
\text { minor } \\
\text { concern of } \\
\text { shifting the } \\
\text { focus from } \\
\text { other health } \\
\text { concerns in } \\
\text { LTC (e.g. } \\
\text { pressure } \\
\text { ulcers) }\end{array}$} \\
\hline & & $\begin{array}{l}\text { - Train the trainer - with } \\
\text { follow-up support with } \\
\text { multiple touchpoints, } \\
\text { feedback, and regular } \\
\text { positive reinforcement }\end{array}$ & & \\
\hline & & $\begin{array}{l}\text { - Train the early change } \\
\text { adopters to be trainers }\end{array}$ & & \\
\hline \multirow[t]{9}{*}{$\begin{array}{l}\text { Environmental } \\
\text { restructuring }\end{array}$} & \multirow[t]{4}{*}{$\begin{array}{l}\text { Culture } \\
\text { change }\end{array}$} & $\begin{array}{l}\text { - Change the social } \\
\text { context by empowering } \\
\text { PSWs, volunteers, and } \\
\text { families }\end{array}$ & \multirow[t]{4}{*}{$\begin{array}{l}\text { LTC home policy } \\
\text { and practices } \\
\text { change }\end{array}$} & \multirow{4}{*}{$\begin{array}{l}\text { May not be } \\
\text { acceptable to } \\
\text { some due to } \\
\text { sharing of } \\
\text { power. } \\
\text { Potential side } \\
\text { effect of } \\
\text { individuals } \\
\text { performing } \\
\text { tasks out of } \\
\text { their scope. }\end{array}$} \\
\hline & & $\begin{array}{l}\text { - Changing model of care } \\
\text { to better include } \\
\text { physicians and } \\
\text { pharmacists }\end{array}$ & & \\
\hline & & - Consistent staffing & & \\
\hline & & $\begin{array}{l}\text { - Promote team } \\
\text { responsibility and promote } \\
\text { inclusivity }\end{array}$ & & \\
\hline & \multirow{4}{*}{$\begin{array}{l}\text { Resident- } \\
\text { centered care }\end{array}$} & $\begin{array}{l}\text { - Sharing the CAP or } \\
\text { assessment results with }\end{array}$ & Electronic portal. & \multirow{2}{*}{$\begin{array}{l}\text { Family } \\
\text { sharing portal } \\
\text { may be costly } \\
\text { to develop. }\end{array}$} \\
\hline & & residents and families & \multirow[t]{3}{*}{$\begin{array}{l}\text { Resident-family } \\
\text { conferences }\end{array}$} & \\
\hline & & $\begin{array}{l}\text { - Family and resident-led } \\
\text { huddles with staff during } \\
\text { quarterly and annual } \\
\text { reviews }\end{array}$ & & \multirow{2}{*}{$\begin{array}{l}\text { May not be } \\
\text { practicable, } \\
\text { effective, or } \\
\text { acceptable } \\
\text { due to cost } \\
\text { and lack of } \\
\text { interest or } \\
\text { availability } \\
\text { for some } \\
\text { families. }\end{array}$} \\
\hline & & $\begin{array}{l}\text { - Working with family to } \\
\text { balance individual rights, } \\
\text { autonomy, freedom, and } \\
\text { safety }\end{array}$ & & \\
\hline & $\begin{array}{l}\text { Physical } \\
\text { restructuring }\end{array}$ & $\begin{array}{l}\text { - Physical modifications to } \\
\text { the LTC home to reduce } \\
\text { fractures and promote } \\
\text { collaboration (e.g. } \\
\text { handrails, open space) }\end{array}$ & $\begin{array}{l}\text { Physical changes } \\
\text { to the layout of } \\
\text { the LTC home }\end{array}$ & $\begin{array}{l}\text { Not } \\
\text { discussed }\end{array}$ \\
\hline
\end{tabular}




\begin{tabular}{|c|c|c|c|c|}
\hline \multirow[t]{4}{*}{$\begin{array}{l}\text { BCW } \\
\text { Intervention } \\
\text { function }\end{array}$} & \multirow[t]{2}{*}{ Themes } & \multirow{2}{*}{$\begin{array}{l}\text { Interventions in the } \\
\text { context of implementing } \\
\text { the Fracture Risk CAP } \\
\text { - Making the CAP easily } \\
\text { accessible to all members } \\
\text { on the care team }\end{array}$} & Mode of Delivery & \multirow[t]{2}{*}{$\begin{array}{l}\text { Does it meet } \\
\text { APEASE? }\end{array}$} \\
\hline & & & Virtual dashboard & \\
\hline & \multirow[t]{2}{*}{$\begin{array}{l}\text { Minimize any } \\
\text { increase in } \\
\text { workload }\end{array}$} & $\begin{array}{l}\text { - Standardized process } \\
\text { once a high FRS score is } \\
\text { generated }\end{array}$ & \multirow[t]{2}{*}{ Care processes } & \multirow[t]{2}{*}{ Yes } \\
\hline & & $\begin{array}{l}\text { - Integration of the CAP } \\
\text { into the existing processes } \\
\text { (e.g. annual care } \\
\text { conferences) }\end{array}$ & & \\
\hline Enablement & $\begin{array}{l}\text { Software } \\
\text { features }\end{array}$ & $\begin{array}{l}\text { - Software add-on with the } \\
\text { following features: flags } \\
\text { staff only when } \\
\text { meaningful changes } \\
\text { occur, provide easy access } \\
\text { to historical data, identify } \\
\text { actionable things, perhaps } \\
\text { targeted to person who } \\
\text { can implement }\end{array}$ & Software & $\begin{array}{l}\text { Development } \\
\text { time may not } \\
\text { be } \\
\text { practicable. } \\
\text { Side-effect: } \\
\text { alarm fatigue } \\
\text { taking away } \\
\text { attention } \\
\text { from other } \\
\text { health } \\
\text { conditions. }\end{array}$ \\
\hline \multirow[t]{2}{*}{ Modeling } & \multirow[t]{2}{*}{$\begin{array}{l}\text { Building } \\
\text { modeling into } \\
\text { training }\end{array}$} & $\begin{array}{l}\text { - Case-study } \\
\text { - Build into education by } \\
\text { role-playing }\end{array}$ & \multirow[t]{2}{*}{$\begin{array}{l}\text { In-person, } \\
\text { videos }\end{array}$} & \multirow[t]{2}{*}{$\begin{array}{l}\text { Not } \\
\text { discussed. }\end{array}$} \\
\hline & & $\begin{array}{l}\text { - Collaboration with } \\
\text { multiple disciplines during } \\
\text { the training stage to } \\
\text { model real-life }\end{array}$ & & \\
\hline \multirow[t]{3}{*}{ Education } & \multirow[t]{3}{*}{$\begin{array}{l}\text { Education for } \\
\text { staff }\end{array}$} & $\begin{array}{l}\text { - Resources \& materials } \\
\text { tailored to different roles, } \\
\text { easy to access to } \\
\text { reference tool that can be } \\
\text { taken to bedside and used } \\
\text { as part of training e.g., on } \\
\text { tablet, on website }\end{array}$ & \multirow[t]{3}{*}{$\begin{array}{l}\text { Micro-learning } \\
\text { and E-learning } \\
\text { sessions, } \\
\text { annual in-service, } \\
\text { professional } \\
\text { advisory meetings }\end{array}$} & \multirow{3}{*}{$\begin{array}{l}\text { More } \\
\text { affordable if } \\
\text { it's online. } \\
\text { Potential side } \\
\text { effect of } \\
\text { people } \\
\text { burning out } \\
\text { from training } \\
\text { and time } \\
\text { taken away } \\
\text { from staff. }\end{array}$} \\
\hline & & $\begin{array}{l}\text { - Patient-focused } \\
\text { education for staff with } \\
\text { simple and clear } \\
\text { messaging }\end{array}$ & & \\
\hline & & $\begin{array}{l}\text { - Take an interprofessional } \\
\text { approach and improve } \\
\text { physician involvement }\end{array}$ & & \\
\hline
\end{tabular}




\begin{tabular}{|c|c|c|c|c|}
\hline $\begin{array}{l}\text { BCW } \\
\text { Intervention } \\
\text { function }\end{array}$ & Themes & $\begin{array}{l}\text { Interventions in the } \\
\text { context of implementing } \\
\text { the Fracture Risk CAP }\end{array}$ & Mode of Delivery & $\begin{array}{l}\text { Does it meet } \\
\text { APEASE? }\end{array}$ \\
\hline & $\begin{array}{l}\text { Education for } \\
\text { residents and } \\
\text { families }\end{array}$ & $\begin{array}{l}\text { - Importance of guidelines } \\
\text { and how to advocate for } \\
\text { following guidelines }\end{array}$ & $\begin{array}{l}\text { One-page } \\
\text { pamphlet with } \\
\text { actionable items, } \\
\text { resident-family } \\
\text { conferences }\end{array}$ & $\begin{array}{l}\text { Yes, as long } \\
\text { as it is } \\
\text { targeted to } \\
\text { those at high } \\
\text { fracture risk, } \\
\text { available in } \\
\text { multiple } \\
\text { formats, } \\
\text { factually } \\
\text { accurate, and } \\
\text { easy to } \\
\text { understand. }\end{array}$ \\
\hline \multirow[t]{4}{*}{ Persuasion } & \multirow{4}{*}{$\begin{array}{l}\text { Persuasion } \\
\text { through } \\
\text { stories }\end{array}$} & \multirow{2}{*}{$\begin{array}{l}\text { - Highlighting patient } \\
\text { stories / identifying an } \\
\text { important problem to } \\
\text { show the impact of } \\
\text { fractures }\end{array}$} & Posters or videos & \multirow{4}{*}{$\begin{array}{l}\text { Yes, as long } \\
\text { as the visuals } \\
\text { are made for } \\
\text { the home, } \\
\text { include } \\
\text { gender and } \\
\text { racial } \\
\text { diversity, } \\
\text { available in } \\
\text { multi-media } \\
\text { formats, and } \\
\text { changed } \\
\text { regularly }\end{array}$} \\
\hline & & & \multirow[t]{3}{*}{$\begin{array}{l}\text { Social media and } \\
\text { announcement } \\
\text { channel or screen } \\
\text { in LTC homes }\end{array}$} & \\
\hline & & $\begin{array}{l}\text { - Value proposition by } \\
\text { storytelling }\end{array}$ & & \\
\hline & & $\begin{array}{l}\text { - Highlight reduced } \\
\text { workload and increased } \\
\text { QoL related to guideline } \\
\text { usage }\end{array}$ & & \\
\hline \multirow[t]{3}{*}{ Incentivization } & Social reward & $\begin{array}{l}\text { - Recognition from } \\
\text { organizations (i.e. } \\
\text { Osteoporosis Canada) }\end{array}$ & $\begin{array}{l}\text { Acknowledgement } \\
\text { from organization } \\
\text { - hard (i.e., } \\
\text { plaque) or soft } \\
\text { (i.e., seal of } \\
\text { approval on } \\
\text { website) copy }\end{array}$ & $\begin{array}{l}\text { Not } \\
\text { discussed }\end{array}$ \\
\hline & \multirow[t]{2}{*}{$\begin{array}{l}\text { Material } \\
\text { reward }\end{array}$} & $\begin{array}{l}\text { - Award the ward with the } \\
\text { lowest fracture rate }\end{array}$ & \multirow{2}{*}{$\begin{array}{l}\text { Financial, food } \\
\text { (e.g., pizza party), } \\
\text { material good } \\
\text { (e.g., t-shirts) }\end{array}$} & \multirow[t]{2}{*}{$\begin{array}{l}\text { Not } \\
\text { discussed }\end{array}$} \\
\hline & & $\begin{array}{l}\text { - Flip case-mix funding to } \\
\text { incentivize functional } \\
\text { improvement, since the } \\
\text { current case-mix model } \\
\text { decreases that incentive }\end{array}$ & & \\
\hline Coercion & $\begin{array}{l}\text { Public } \\
\text { benchmarking }\end{array}$ & $\begin{array}{l}\text { - Public benchmarking, } \\
\text { against Canadian } \\
\text { provinces or other } \\
\text { countries }\end{array}$ & $\begin{array}{l}\text { Publicly } \\
\text { accessible online } \\
\text { dashboard }\end{array}$ & $\begin{array}{l}\text { Potential side } \\
\text { effect of } \\
\text { underreported } \\
\text { cases. }\end{array}$ \\
\hline
\end{tabular}




\begin{tabular}{|c|c|c|c|c|}
\hline $\begin{array}{l}\text { BCW } \\
\text { Intervention } \\
\text { function }\end{array}$ & Themes & $\begin{array}{l}\text { Interventions in the } \\
\text { context of implementing } \\
\text { the Fracture Risk CAP }\end{array}$ & Mode of Delivery & $\begin{array}{l}\text { Does it meet } \\
\text { APEASE? }\end{array}$ \\
\hline \multirow[t]{2}{*}{ Restriction } & \multirow[t]{2}{*}{ Regulations } & $\begin{array}{l}\text { - FRS score and } \\
\text { associated care plan as } \\
\text { criteria for use of } \\
\text { osteoporosis medication }\end{array}$ & \multirow[t]{2}{*}{$\begin{array}{l}\text { Policies and } \\
\text { procedures }\end{array}$} & \multirow[t]{2}{*}{$\begin{array}{l}\text { Not } \\
\text { discussed }\end{array}$} \\
\hline & & $\begin{array}{l}\text { - Ministry of Health } \\
\text { mandates use of up-to- } \\
\text { date Fracture Risk } \\
\text { Assessment and } \\
\text { Prevention Tools }\end{array}$ & & \\
\hline \multicolumn{5}{|c|}{ LTC $=$ Long term care } \\
\hline \multicolumn{5}{|c|}{ FRS $=$ Fracture Risk Scale } \\
\hline \multicolumn{5}{|c|}{$\mathrm{CAP}=$ Clinical assessment protocol } \\
\hline \multicolumn{5}{|c|}{ BCW = Behaviour Change Wheel } \\
\hline
\end{tabular}

\section{Discussion}

In this study, we conducted focus group interviews with LTC stakeholders to identify KT interventions for implementing the Fracture Risk CAP. Among fourteen intervention themes, four met the APEASE criteria. The four intervention themes that met the APEASE criteria were minimizing any increase in workload, training on CAP usage, education for residents and families, and persuasion through stories. Other intervention themes in Table 3 may also be considered depending on the context (i.e. availability of resources). Many of the interventions identified could be generalized to implement other guidelines or tools in the LTC setting though the specific interventions were discussed in the context of implementing the Fracture Risk CAP. For example, while KT interventions like software add-ons and physical restructuring may not be applicable to most guidelines, strategies that address education and include modeling are likely needed across many guidelines.

An intervention theme that was strongly recommended by the participants and met the APEASE criteria is minimizing any workload increase associated with the guidelines. Indeed, frequently reported barriers across many guideline topics include lack of time and lack of staff [28]. Since staffing and workload is often a concern in the LTC sector, implementing new guidelines in LTC homes should not overburden the staff. Using standardized processes in LTC to simplify and decrease the workload has been recommended in the literature [29]. However, exclusive institutional reliance on standardized processes may fail to achieve individualized care planning, so residents' preferences and input by care aides should be considered [30]. Leveraging existing processes in the LTC homes may also be a way to minimize workload. Examples of processes in LTC homes that could be leveraged for implementing the Fracture Risk CAP include discussing its usage during annual care conferences and adding it to the Exercise and Falls Prevention Program in Ontario [31]. 
Several interventions discussed by multiple focus groups fall under the theme "culture change", which encompasses changing the social context to empower personal support workers (or care aides), volunteers, and families, integrating physicians and pharmacists in the care team, having consistent staffing, and promoting team responsibility. Care aides are workers who have the most direct contact with LTC residents, but also those who have the "least training, authority, and status within the system" [32]. Interestingly, empowering care aides and ensuring consistent staffing can positively influence resident outcomes including lower pressure ulcer incidence rates and higher social engagement scores [33]. Similarly, empowerment of nursing assistants improved service quality more than the empowerment of nurses [34], which demonstrates the importance of focusing on this role in LTC. On the other hand, physicians and pharmacists often travel between LTCs. Consequently, health conditions such as fracture risk that are often placed at low priority compared to more acute conditions such as heart diseases are sometimes overlooked despite their severe consequences [35, 36]. However, evidence suggest that including pharmacists and physicians on the care team could reduce medication costs and hospital transfers [37,38]. For countries where there is a lack of elderly care physicians, a study has also suggested substituting with nurse practitioners and physician assistants in appropriate contexts [39]. Among the LTC stakeholders in our study, there is concern of individuals performing tasks out of their scope when promoting team responsibility. Nevertheless, the call for redesigning roles and ensuring that all the interprofessional team members can contribute in LTC is consistent with previous literature [40] and is especially pronounced during the COVID-19 pandemic [41].

Another frequently discussed theme were interventions that promoted resident-centered care. Our focus group participants suggested keeping residents informed by sharing assessment results with them and their families, encouraging family and resident-led huddles with staff during annual reviews, and working with family to balance individual rights, autonomy, and safety. According to a recent systematic review on the effects of person-centered care in aged-care facilities, the complexity of the interventions and range of outcomes makes it difficult to form accurate conclusions and more research is needed to establish the effectiveness of person-centred interventions [42]. Nevertheless, the review suggests that the introduction of person-centered care should be incorporated while considering residents' safety and physiological needs, since the review identified studies that reported higher incidence of falls in person-centred care than in usual care [42]. Of note, another study reported differing perspectives on varying facets of resident-centred care between residents and staff, which highlights the importance of including both the care team and residents in the discussion when attempting to improve person-centred care [43].

A strength of our study is the use of a comprehensive framework to guide the design and analysis of KT interventions. Our behaviour change theory-informed approach allowed us to generate a systematic understanding of implementation problems and the generation of interventions to overcome those problems. Thus, the identified KT interventions are more likely to be successful. Another strength is the wide range of roles in LTC that we consulted to identify and evaluate the feasibility of the interventions, which offers many different perspectives for how to best implement the Fracture Risk CAP. We also recognize several limitations of the study. Due to time constraints, our focus group participants did not fully discuss the APEASE evaluation for all the interventions. Therefore, some interpretation of 
conversations was required by the authors. Moreover, there is subjectivity in how we encoded the interventions into different themes and intervention functions. There are several possible ways link intervention to intervention types that depends on interpretation of transcripts. While we evaluated the feasibility of most KT interventions using the APEASE criteria in consultation with stakeholders, we could not conclude which ones are most effective. Our next steps are to prioritize and examine the effectiveness of these interventions to change practice and influence resident outcomes as we implement the Fracture Risk CAP.

\section{Conclusions And Implications}

Guided by the BCW and in consultation with LTC stakeholders, we identified several KT interventions that are feasible to overcome anticipated barriers to implementing evidence-based guidelines in LTC homes. Intervention themes recommended based on APEASE are minimizing any increase in workload, training on CAP usage, education for residents and families, and persuasion through stories. Other intervention themes that may be considered are culture change, resident-centred care, physical restructuring, software features, modeling in training, education for staff, social rewards, material rewards, public benchmarking, and regulations. Results from this work will be essential to increase usage of the Fracture Risk CAP and improve identification and management of LTC residents at high fracture risk. We suggest that futures researchers interested in KT to identify unique barriers and facilitators for their guideline topic in addition to general barriers and consider a theory-informed approach to develop implementation strategies.

\section{Abbreviations}

LTC: Long-term care

CAP: Clinical assessment protocol

FRS: Fracture Risk Scale

KT: Knowledge translation

BCW: Behaviour Change Wheel

COM-B: Capability, opportunity, motivation, behaviour

APEASE: Affordability, Practicability, Effectiveness, Acceptability, Safety, Equity

\section{Declarations}

\section{Ethics approval and consent to participate}

This project was conducted in accordance to the Declaration of Helsinki and approved by the Hamilton Integrated Research Ethics Board. All participants provided informed consent to participate in the study. 


\section{Consent for publication}

Not applicable

\section{Availability of data and material}

The datasets generated and/or analysed during the current study are not publicly available due to limits placed on who has access to data during the informed consent process but are available from the corresponding author on reasonable request.

\section{Competing interests}

The authors declare no competing interests.

\section{Funding}

CM was supported by a fellowship from the Canadian Institutes of Health Research. YB was supported by a summer studentship from the McMaster Institute for Research on Aging. The funder had no role in the study, interpretation of data, or decision to submit results.

\section{Authors' contributions}

$\mathrm{CM}$ and YB conceptualized the study, conducted data analysis, interpreted the results, and wrote the manuscript. GI, LG, SS and AP provided content expertise and assisted with interpretation of the results. All authors critically read, contributed to, and approved the manuscript for submission. The funder had no role in the study, interpretation of data, or decision to submit results.

\section{Acknowledgements}

We would like to thank Gianluca Sorrento, Loretta Hillier, and Jessica Belgrave for facilitating the focus group interviews.

\section{References}

1. Papaioannou A, Kennedy CC, loannidis G, Sawka A, Hopman WM, Pickard L, et al. The impact of incident fractures on health-related quality of life: 5 years of data from the Canadian Multicentre Osteoporosis Study. Osteoporos Int J Establ Result Coop Eur Found Osteoporos Natl Osteoporos Found USA. 2009 May;20(5):703-14.

2. Amarilla-Donoso FJ, López-Espuela F, Roncero-Martín R, Leal-Hernandez O, Puerto-Parejo LM, AliagaVera I, et al. Quality of life in elderly people after a hip fracture: a prospective study. Health Qual Life Outcomes [Internet]. 2020 Mar 14 [cited 2020 Aug 29];18. Available from: https://www.ncbi.nlm.nih.gov/pmc/articles/PMC7071575/ 
3. Zimmerman SI, Girman CJ, Buie VC, Chandler J, Hawkes W, Martin A, et al. The prevalence of osteoporosis in nursing home residents. Osteoporos Int $\mathrm{J}$ Establ Result Coop Eur Found Osteoporos Natl Osteoporos Found USA. 1999;9(2):151-7.

4. Papaioannou A, Kennedy CC, loannidis G, Cameron C, Croxford R, Adachi JD, et al. Comparative trends in incident fracture rates for all long-term care and community-dwelling seniors in Ontario, Canada, 2002-2012. Osteoporos Int J Establ Result Coop Eur Found Osteoporos Natl Osteoporos Found USA. 2016 Mar;27(3):887-97.

5. Beaupre LA, Cinats JG, Jones CA, Scharfenberger AV, William C Johnston D, Senthilselvan A, et al. Does functional recovery in elderly hip fracture patients differ between patients admitted from longterm care and the community? J Gerontol A Biol Sci Med Sci. 2007 Oct;62(10):1127-33.

6. Rapp K, Becker C, Lamb SE, Icks A, Klenk J. Hip Fractures in Institutionalized Elderly People: Incidence Rates and Excess Mortality. J Bone Miner Res. 2008;23(11):1825-31.

7. Neuman MD, Silber JH, Magaziner JS, Passarella MA, Mehta S, Werner RM. Survival and Functional Outcomes After Hip Fracture Among Nursing Home Residents. JAMA Intern Med. 2014 Aug 1;174(8):1273-80.

8. Wall M, Lohfeld L, Giangregorio L, loannidis G, Kennedy CC, Moser A, et al. Fracture risk assessment in long-term care:a survey of long-term care physicians. BMC Geriatr. 2013 Oct 18;13(1):109.

9. Compston J. Reducing the treatment gap in osteoporosis. Lancet Diabetes Endocrinol. 2020 Jan 1;8(1):7-9.

10. Bravo G, Dubois M-F, De Wals P, Hébert R, Messier L. Relationship between Regulatory Status, Quality of Care, and Three-Year Mortality in Canadian Residential Care Facilities: A Longitudinal Study. Health Serv Res. 2002 Oct;37(5):1181-96.

11. Leslie WD, Berger C, Langsetmo L, Lix LM, Adachi JD, Hanley DA, et al. Construction and validation of a simplified fracture risk assessment tool for Canadian women and men: results from the CaMos and Manitoba cohorts. Osteoporos Int J Establ Result Coop Eur Found Osteoporos Natl Osteoporos Found USA. 2011 Jun;22(6):1873-83.

12. Leslie WD, Lix LM, Langsetmo L, Berger C, Goltzman D, Hanley DA, et al. Construction of a FRAX® model for the assessment of fracture probability in Canada and implications for treatment. Osteoporos Int. 2011 Mar;22(3):817-27.

13. Khatib R, Santesso N, Pickard L, Osman O, Giangregorio L, Skidmore C, et al. Fracture risk in long term care: a systematic review and meta-analysis of prospective observational studies. BMC Geriatr. $2014 \operatorname{Dec} 3 ; 14(1): 130$.

14. Graham ID, Logan J, Harrison MB, Straus SE, Tetroe J, Caswell W, et al. Lost in knowledge translation: time for a map? J Contin Educ Health Prof. 2006;26(1):13-24.

15. McArthur C, Hillier L, loannidis G, Adachi JD, Giangregorio L, Hirdes J, et al. Developing a Fracture Risk Clinical Assessment Protocol for Long-Term Care: A Modified Delphi Consensus Process. J Am Med Dir Assoc [Internet]. 2020 Sep 21 [cited 2020 Sep 28]; Available from: http://www.sciencedirect.com/science/article/pii/S1525861020307052 
16. Morris J, Berg K, Bjorkgren M, Finne-Soveri H, Fries B, Frijters D. interRAI Clinical Assessment Protocols (CAPs) for Use with Community and Long-Term Care Assessment Instruments. Wash DC InterRAl. Version 9.1. 2010.

17. Morris, J., Belleville-Taylor, P., Fries, B., Hawes, C., Murphy, K. and Mor, V., 2009. InteRAI Long-Term Care Facilities (LTCF) Assessment Form and User'S Manual. Version 9.1. Washington, DC: interRAl.

18. Ioannidis G, Jantzi M, Bucek J, Adachi JD, Giangregorio L, Hirdes J, et al. Development and validation of the Fracture Risk Scale (FRS) that predicts fracture over a 1-year time period in institutionalised frail older people living in Canada: an electronic record-linked longitudinal cohort study. BMJ Open [Internet]. 2017 Sep 1 [cited 2020 Aug 29];7(9). Available from:

https://www.ncbi.nlm.nih.gov/pmc/articles/PMC5588955/

19. Papaioannou A, Santesso N, Morin SN, Feldman S, Adachi JD, Crilly R, et al. Recommendations for preventing fracture in long-term care. CMAJ. 2015 Oct 20;187(15):1135-44.

20. Mickan S, Burls A, Glasziou P. Patterns of 'leakage' in the utilisation of clinical guidelines: a systematic review. Postgrad Med J. 2011 Oct;87(1032):670-9.

21. Bauer MS. A review of quantitative studies of adherence to mental health clinical practice guidelines. Harv Rev Psychiatry. 2002 Jun;10(3):138-53.

22. Grol R. Successes and failures in the implementation of evidence-based guidelines for clinical practice. Med Care. 2001 Aug;39(8 Suppl 2):I146-54.

23. Specht JK. Evidence Based Practice in Long Term Care Settings. J Korean Acad Nurs. 2013 Apr $1 ; 43(2): 145-53$.

24. Walker M, French SD, Feldman-Stewart D, Siemens DR, Mackillop WJ, Booth CM. A call for theoryinformed approaches to knowledge translation studies: an example of chemotherapy for bladder cancer. Curr Oncol. 2015 Jun;22(3):178-81.

25. Michie S, van Stralen MM, West R. The behaviour change wheel: A new method for characterising and designing behaviour change interventions. Implement Sci. 2011 Apr 23;6(1):42.

26. Roberts K, Dowell A, Nie J-B. Attempting rigour and replicability in thematic analysis of qualitative research data; a case study of codebook development. BMC Med Res Methodol. 2019 Mar 28;19(1):66.

27. Braun V, Clarke V. Thematic analysis https://. Accessed 20 Sep 2020.

28. Brazil K, Maitland J, Ploeg J, Denton M. Identifying research priorities in long term care homes. J Am Med Dir Assoc. 2012 Jan;13(1):84.e1-4.

29. Ghogomu E, Kuurstra E, Donskov M, Ghaedi B, Richardson, K. Implementation of care planning in long term care. Bruyère Rep. 2017 Jan;(7).

30. Kontos PC, Miller K-L, Mitchell GJ. Neglecting the Importance of the Decision Making and Care Regimes of Personal Support Workers: A Critique of Standardization of Care Planning Through the RAI/MDS. The Gerontologist. 2010 Jun;50(3):352-62. 
31. Registered Nurses' Association of Ontario. Toolbox for Implementation of a Falls Prevention Program in Long-Term Care. [Internet]. Nursing Best Practice Guidelines Program; 2007. Available from: https://rnao.ca/sites/rnaoca/files/Toolbox_for_Implementation_of_a_Falls_Prevention_Program_in_Long-Term_Care.pdf

32. Zysberg L, Band-Winterstein T, Doron I, Shulyaev K, Siegel EO, Kornas-Biela D, et al. The health care aide position in nursing homes: A comparative survey of nurses' and aides' perceptions. Int J Nurs Stud. 2019 Jun;94:98-106.

33. Barry T "Teta," Brannon D, Mor V. Nurse Aide Empowerment Strategies and Staff Stability: Effects on Nursing Home Resident Outcomes. The Gerontologist. 2005 Jun;45(3):309-17.

34. Hamann DJ. Does empowering resident families or nursing home employees in decision making improve service quality? J Appl Gerontol Off J South Gerontol Soc. 2014 Aug;33(5):603-23.

35. Claesson A, Toth-Pal E, Piispanen P, Salminen H. District nurses' perceptions of osteoporosis management: a qualitative study. Osteoporos Int J Establ Result Coop Eur Found Osteoporos Natl Osteoporos Found USA. 2015 Jul;26(7):1911-8.

36. McKercher HG, Crilly RG, Kloseck M. Osteoporosis management in long-term care. Survey of Ontario physicians. Can Fam Physician. 2000 Nov;46:2228-35.

37. Kwak A, Yj M, Yk S, Hy Y, K K. Economic Impact of Pharmacist-Participated Medication Management for Elderly Patients in Nursing Homes: A Systematic Review. Int J Environ Res Public Health [Internet]. 2019 Aug 16 [cited 2020 Aug 29];16(16). Available from: https://europepmc.org/article/pmc/6721063

38. Brühmann BA, Reese C, Kaier K, Ott M, Maurer C, Kunert S, et al. A complex health services intervention to improve medical care in long-term care homes: study protocol of the controlled coordinated medical care (CoCare) study. BMC Health Serv Res. 2019 May 24;19(1):332.

39. Lovink MH, Laurant MG, van Vught AJ, Maassen I, Schoonhoven L, Persoon A, et al. Substituting physicians with nurse practitioners, physician assistants or nurses in nursing homes: a realist evaluation case study. BMJ Open. 2019 24;9(5):e028169.

40. Keboa M, Beaudin A, Cyr J, Decoste J, Power F, Hovey R, et al. Dentistry and nursing working together to improve oral health care in a long-term care facility. Geriatr Nurs N Y N. 2019 Apr;40(2):197-204.

41. McGilton KS, Escrig-Pinol A, Gordon A, Chu CH, Zúñiga F, Sanchez MG, et al. Uncovering the Devaluation of Nursing Home Staff During COVID-19: Are We Fuelling the Next Health Care Crisis? J Am Med Dir Assoc. 2020 Jul;21(7):962-5.

42. Brownie S, Nancarrow S. Effects of person-centered care on residents and staff in aged-care facilities: a systematic review. Clin Interv Aging. 2013;8:1-10.

43. Yang Y, Li H, XIAO LD, Zhang W, Xia M, Feng H. Resident and staff perspectives of person-centered climate in nursing homes: a cross-sectional study. BMC Geriatr. 2019 Oct 29;19(1):292.

\section{Figures}




\section{Understanding the}

Behaviour

क्

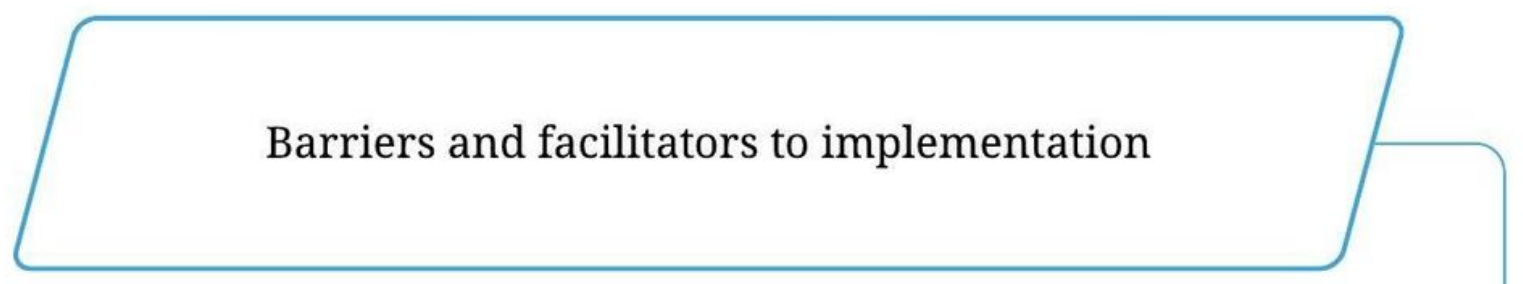

Systematic review (reported elsewhere) \& focus group discussion

\section{Identify intervention options}

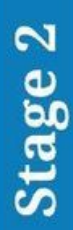

Intervention options within nine intervention functions provided by the BCW

Focus group discussions

\section{Identify content and implementation options}
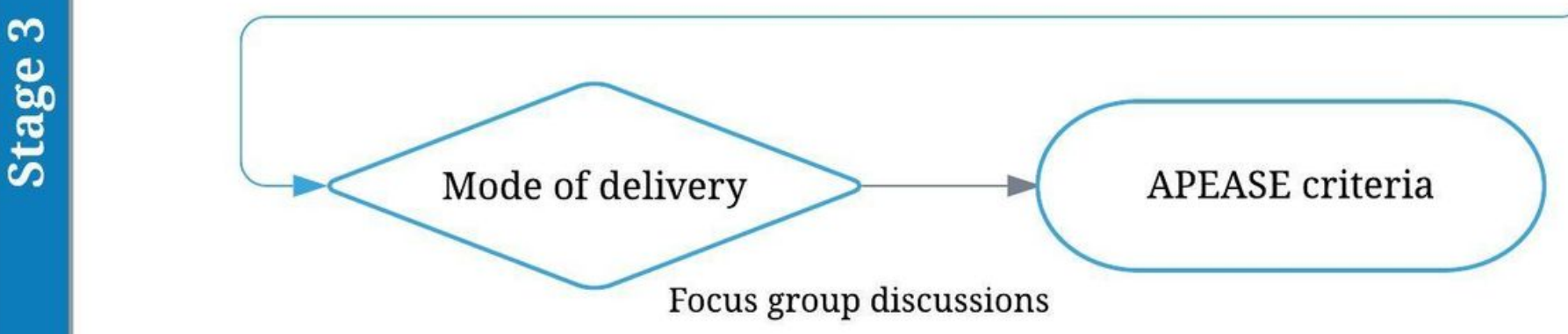

Figure 1

Flowchart of methods informed by the BCW

\section{Supplementary Files}

This is a list of supplementary files associated with this preprint. Click to download.

- AdditionalFile1.pdf

- AdditionalFile2.pdf 
- AdditionalFile3.pdf

Page 21/21 